\title{
Gender Stereotypes in Advertising
}

\author{
Anna Kniazian \\ Yerevan State University
}

\begin{abstract}
The portrayal of men and women in advertising has received considerable attention over the last several decades, both by practitioners and academics. Research has primarily focused on the visual portrayal of men and women in advertising, within the realm of which, there appears to be a fundamental difference in the way men and women are portrayed. Men are generally stereotyped as competent, assertive, independent, and achievement oriented, whereas women are generally stereotyped as warm, sociable, interdependent, and relationship-oriented. Women are more often portrayed as young and concerned with physical attractiveness than their male counterparts. Masculine and feminine stereotypes are complementary in the sense that each gender group is seen as possessing a set of strengths that balance out their own weaknesses and that supplement the assumed strengths of the other group.
\end{abstract}

Key words: gender advertising, gender roles, masculine and feminine stereotypes in TV advertising.

\section{Introduction}

Human differentiation on the basis of gender is a fundamental phenomenon that affects virtually every aspect of people's daily lives. Gender can be defined as the sex-role that a person takes on according to standards instilled in us by society. The traditional roles of men and women are different and they are developed in their childhood, moreover their behaviors are differentiated when being little boys and girls (Smith 1985). The difficulty in differentiating gender roles in modern societies can be a perfect example of the negative social effect of using stereotypes. The traditional feminine gender role is a social orientation that emphasizes closeness and solidarity, whereas the traditional masculine gender role is a social orientation that emphasizes power and status (Henley, Kramarae 1991).

A division of gender roles is deeply rooted in the social archetypes. Through the ages men have been considered to be financial providers, career-focused, assertive and independent, whereas women have been shown as low-position workers, loving wives and mothers, responsible for raising children and doing housework. Nowadays a family model is based rather on a partnership than on patriarchy, and women have more rights and possibilities. Feminist environment had a significant impact on the change in this situation. Although females and males are still not equal, the differences between gender are not so vast anymore. Nevertheless, many social institutions, such as mass media, still use gender stereotypes, proceeding from the assumption, that they are well known to everyone and help the receivers to understand the content of the message. People organize their knowledge about the world, by sorting and simplifying the received information. Therefore, they create cognitive schemes, which are certain representations 
of the reality displaying its most typical and fundamental elements and properties. These schemes are responsible for defining the essence of our worldview and have a significant influence on understanding and anticipation. Stereotypes are the most important types of schemes used for orientation in the social environment. They can be the result of our own observations or be adopted from the influence of the social environment, such as family, friends, teachers and media. But stereotypes present incomplete, subjective and sometimes false image of the reality. They are often based on tradition and are resistant to change. However, they can be not only negative but also positive.

Gender stereotypes occur in communication patterns, habits, and traditions across cultures, proving that gender communication is a form of intercultural communication. The role of culture in communication practices directs us to an intercultural perspective on gender and communication (Penington 1985).

\section{Gender and Mass Media}

Gender stereotypes in the mass media have a great power and reach large audiences. In order to create a medium which is universal, understandable and acceptable for numerous and diverse recipients, senders of message very often use stereotypes, which fill the social life and evoke certain associations. However, mass media not only gives people information and entertainment, but, according to theCanadian communication theorist Marshall McLuhan, it also affects people's lives by shaping their opinions, attitudes and beliefs (McLuhan 1964).

Commercial radio and television channels, newspapers, magazines, the Internet are today present in countries all over the globe, and advertisements, commercials are a natural part of people's lives. Companies use different media to reach out to potential and existing consumers.

Commercial television has spread worldwide since the seventies and most people are today subjected to a great quantity of television advertisements (Furnham, Mak 1999). There exists a huge interest among marketing researchers in gender-related research, since gender is one of the largest segmentation variables (Milner and Collins, 2000; Milner and Higgs 2004).

Research on gender stereotypes in television advertisements was scarce up until the middle of the 1970s. From that time on, however, as television and television advertisements have spread all over the world, an extensive bulk of research has been undertaken (Courtney, Whipple 1974; Furnham, Abramsky, Gunter 1997; Furnham, Skae 1997). Numerous studies in the 1970s systematically demonstrated that both women and men portrayed in the media reflect gender stereotypes. There have been different approaches for gender stereotyping research. Milner and Higgs (2004) argue that the way men and women are portrayed in advertisements is one indicator to measure society's attitudes towards gender. Gunter (1995) argues that gender stereotyping in television affects young people who learn appropriate gender attitudes and behavior. Due to the present situation where companies and organizations use television commercials to reach men, women, and children, there is a significant interest in how gender stereotypes are portrayed in television advertisements (Jennings, Geis, Brown 1980; Kolbe, Langefeld 1993). Hawkins 
and Coney (1976) suggest that different cultural perceptions of what is seen as a proper role for a woman can result in national differences in how women are portrayed in advertisements. Men and women in television advertisements are portrayed following traditional gender stereotypes (Furnha, Mak 1999). It is the television advertisements that influence the mode society views appropriate roles for men and women. The studies indicate that there are more men than women in television advertisements (Furnham, Bitar 1993; Furnham, Babitzkow, Uguccioni 2000). Men often occupy dominant roles, a professional expert or interviewer. Men have been perceived as the head of the household, and women were mainly housewives. Nowadays the differences between male and female roles are smaller, however mass media still perpetuates traditional gender stereotypes. Moreover, due to their great influence on people's attitudes, they can depict certain social groups in negative and unrealistic manner. By manipulating the message, media can create a certain image of reality, which is consistent with the policy of the dominant group. As a result, the reflection of the real world is incomplete and distorted. Although people are aware of the unequal representation of certain social groups in mass media, it is hard to remain objective and insensitive to its influence.

Thus, gender issues in communication have attracted the attention of many researchers. There has been considerable interest in the possible contributions of the mass media to the origins and maintenance of gender roles (Courtney \& Whipple 1974). Gender stereotyping refers to one of the most common tactics used by the media to generalize female and male characteristics, personalities and attributes. By creating a certain type of message, media can manipulate people's attitudes and opinions.

The advertisements of modern times have a great effect on society as a whole. The advertising industry spends countless hours and millions of dollars preparing and shaping the way and place in which a person will view their advertisements. Overtly they help to shape the consuming habits of both men and women, however, the deeper implications of advertisements have an effect on society as well.

It is interesting to examine how stereotypes are reflected in TV advertising. TV advertisements aimed at men differ from those aimed at women. Men appear more often than women in television advertisements. Men and women differ in terms of credibility (men being authorities and women users), role (women are portrayed in terms of their relationship to others and men in a role independent of others), location (men are shown in occupational settings and women at home), persuasive arguments (men give more scientific arguments than women), rewards (women are shown obtaining approval of family and males, while men obtain social and career advancement) and product type (men are authorities on products used primarily by women). Men are portrayed as being aggressive. They are usually in the pursuit of power, speed, wealth, or physical domination. Product names can reflect these traits for men.

Commercials are a vast source of gender stereotyping, because they are adapted to the specific, either male or female target. The aim of the modern commercial is not only the satisfaction of needs but also their creation. Women are seen as responsible for making everyday purchases. Men generally advertise cars, cigarettes, business products or investments, whereas women are shown rather in the commercials with cosmetics and domestic products. They are 
also more likely portrayed in the home environment, unlike men, who are shown outdoors. One can observe mainly the presence of very thin actresses in this type of commercials, which can lead to the assumption, that only thin women can be beautiful and healthy.

Male stereotypes are also various. The first model is "a real man", athletic, successful, professional, seducer with a beautiful woman by his side. He also has a branded car. The other type is less popular and presents men devoted to their families who can save enough time for them. Men are very rarely presented during housecleaning. Men are presented as acting together, for instance by going to a football match or to the pub. They share the same interests and opinions, and they enjoy spending time together by doing something extremely interesting and adventurous.

Women are shown in an entirely different light by the advertising world. Instead of being strong, powerful people in advertisements, women are usually seen in a more domestic role. It is not uncommon for women in ads to be seen as a housewife, mother, or simply cooking. They are put into a passive role. The woman in the advertisement is not aggressive; rather she waits to be selected by the man and then follows his lead. This pushes the message that an attractive, confident woman should focus on being noticed by the other gender instead of taking action. Advertisements more often sexually objectify women's bodies than men's to sell merchandise, and women are more often depicted in a way emphasizing their sexuality. This cultural milieu of sexual objectification functions to socialize girls and women to evaluate their own value based on appearance, and become preoccupied with their own physical appearance. Many women feel pressured to conform to the beauty standards generally accepted in the society and are willing to go to great lengths to manipulate and change their faces and bodies. They are conditioned to view their faces as masks and their bodies as objects, and discover that their bodies and faces are in need of alteration, augmentation, and disguise.

Male and female adult characters are also still clearly associated with activities traditionally connected with their gender. Finally, male characters are often shown alone, participating in stereotypically male behavior. Men are most likely to be portrayed as celebrities in occupational settings or in unspecified locations, while women are most likely dependent on others.

Age is often one of the best indicators of sex-role stereotyping. Studies show that central figures in TV advertisements are dominated by middle-aged males and young females. The depiction of female figures as young is a typical feature of advertisements. This implies that advertisers consider it important for women to be portrayed as youthful and consequently attractive, whereas this is not as important for men. Instead male figures are depicted as being older or middle aged.

The observations show that in advertising males are likely to appear as voice-overs whereas females are depicted visually. The higher proportion of males comprising the voice-over category suggests that men are considered to have knowledge about products more than women. Even advertisements for children feature male voice-overs. Advertisements for girls usually, but not always, use female voice-overs. Although women have a reputation for being more verbal than men, boys are more likely to be speaking in advertisements showing both boys and girls. Usually an adult voice is used 
for the male voice-overs, but about one-sixth of the girl-oriented advertisements use a girl's voice for the voice-over. Voices, whether male or female (Gilligan, Carol 1982), are caricatured in the majority of advertisements, with male voices often sounding unnaturally deep, husky or loud, and female voices unusually high-pitched and squeaky.

There are certain roles where feminine and masculine traits do a better job conveying a particular message. Advertisers have spent mass dollars researching, studying, and attempting to understand these trends so that they can effectively capitalize on them.

\section{Conclusion}

Thus, mass communication, and specifically TV advertising, is a reflection of gender stereotypes in society. Although the image of women depicted in mass media seems to be relatively more positive than in the past, gender stereotypes and inequality through the mass media is still a prominent phenomenon. The presentation of advertisements creates social and cultural norms for those exposed to them. The media reinforces gender differences and stereotypes. Mass mediated messages offer the most contemporary, powerful, technologically and rhetorically sophisticated stereotypes for shaping cultural reality. The main aim of mass media is to be universal and suitable for everyone, in order to gather the largest possible audience. Advertising is a powerful tool used for creating and shaping people's opinions. Advertisement text contains dominant and well-known characteristics of the reality. Male and female stereotypes are very often used in advertisement as one of the most popular techniques of persuasion.

\section{References:}

1. Courtney, A.E. \& Whipple, T.W (1983) Sex Stereotyping in Advertising. Lexington, MA: D.C. Heath.

2. Courtney, A.E. \& Whipple, T.W. (1974) Women in TV Commercials. // Journal of Communication, 24, 110-118.

3. Furnham, A.; Abramsky, S. \& Gunter, B. (1997) A Cross-Cultural Content Analysis of Children's Television Advertisements. // Sex Roles, 37, 91-99. USA: Springer.

4. Furnham, A. and Skae, E. (1997) The Stereotyped Portrayal of Men and Women in British Television Advertisements. // European Psychologist, Vol.2. USA: Hogrefe and Huber Publisher, pp.297-310.

5. Furnham, A.; Babitzkow, M. \& Uguccioni, S. (2000) Gender Stereotyping in Television Advertisement. // A Study of French and Danish Television, Genetic, Social, and General Psychology Monographs, N.126. USA: Heldref Publication, pp.79-104.

6. Furnham, A. \& Mak, T. (1999) Sex-Role Stereotyping in Television Commercials: A Review and Comparison of Fourteen Studies Done on Five Continents Over 25 Years. // Sex Roles, N.41. USA: Springer, pp.413-437.

7. Furnham, A., \& Bitar, N. (1993) The Stereotyped Portrayal of Men and Women in British Television Advertisements. // Sex Roles, N.29. USA: Springer, pp.297-310. 
8. Gilligan, C. (1982) In a Different Voice: Psychological Theory and Women's Development. USA: Harvard University Press.

9. Gunter, B. (1995) Television Gender Representation. London: John Libby.

10. Hawkins, D.I. \& Coney, K.A (1976) Advertising and Differentiated Sex Roles in Contemporary American Society. // Journal of the Academy of Marketing Science, N.4. USA: Springer, pp.418-428.

11. Henley, N.; Kramarae Ch. (1991) Language, Gender and Society. Rowley, MA: Newberry.

12. Jennings, J.; Geis, F.L. and Brown, V. (1980) Influence of Television on Women's SelfConfidence and Independent Judgment. // Journal of Personality and Social Psychology, N.38. USA: Springer, pp.203-210.

13. Kolbe, R. \& Langefeld, C. (1993) Appraising Gender Role Portrayals in TV Commercials. // Sex Roles, N.28. USA: Spring1er, pp.393-417.

14. McLuhan, M. (1964) The Medium is the Message. // Understanding Media: The Extensions of Man. New York: Signet.

15. Milner, L.M. \& Collins, J.M. (2000) Sex-Roles Portrayals and the Gender of Nation. // Journal of Advertising, N.29. USA: Springer, pp. 69-79.

16. Milner, L.M. \& Higgs, B. (2004) Gender Sex-Role Portrayals in International Television Advertising over Time: The Australian Experience. // Journal of Current Issues and Research in Advertising, N.26. New York: Harper, pp.81-95.

17. Penington, D.L. (1985) Intercultural Communication. // Intercultural Communication: A Reader. Eds. Samovar and Porter. Belmont, CA: Wadsworth.

18. Smith, P.M. (1985) Language, the Sexes, and Society. Oxford: Blackwell.

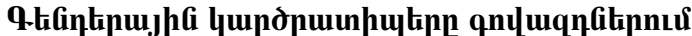

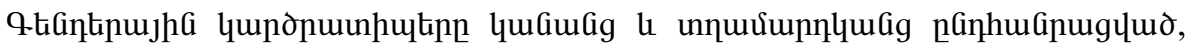

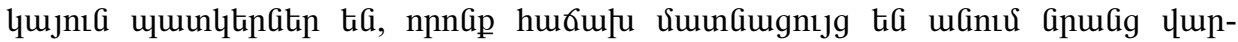

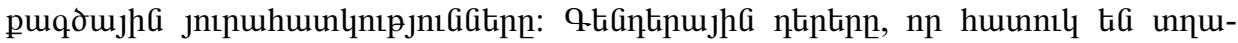

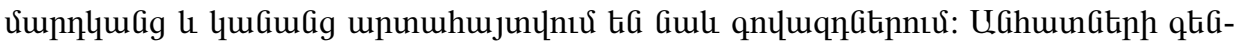

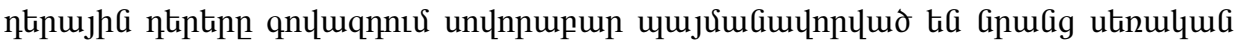

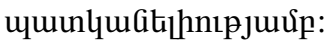

\section{Гендерные стереотипы в рекламе}

Гендерные стереотипы - это некие установки, возникающие над биологически половой реальностью. Они отражают совокупность биологических признаков, социальных ролей, особенностей психики и поведения, присущие представителям данного пола. Характерно, что в рекламе всегда присутствуют гендерные стереотипы, они постоянно формируют образы мужчины и женщины у большинства реципиентов. Реклама обычно закрепляет и усиливает гендерные стереотипы в обществе. 